\title{
Plasmodium vivax and Plasmodium falciparum infections in the Republic of Djibouti: evaluation of their prevalence and potential determinants
}

Bouh Abdi Khaireh ${ }^{1,2,3,4,5+}$, Sébastien Briolant ${ }^{1,2+}$, Aurélie Pascual ${ }^{1,2}$, Madjid Mokrane ${ }^{1,2}$, Vanessa Machault ${ }^{6,7}$, Christelle Travaillé ${ }^{1}$, Mohamed Abdi Khaireh ${ }^{1,2}$, Ismail Hassan Farah ${ }^{3}$, Habib Moussa Ali ${ }^{3}$, Abdul-llah Ahmed Abdi ${ }^{3}$, Souleiman Nour Ayeh ${ }^{4}$, Houssein Youssouf Darar ${ }^{4,8}$, Lénaïck Ollivier ${ }^{9}$, Mohamed Killeh Waiss ${ }^{10}$, Hervé Bogreau ${ }^{1,2}$, Christophe Rogier ${ }^{1,2,11}$ and Bruno Pradines ${ }^{1,2^{*}}$

\begin{abstract}
Background: Formerly known as a hypoendemic malaria country, the Republic of Djibouti declared the goal of pre-eliminating malaria in 2006 . The aim of the present study was to evaluate the prevalence of Plasmodium falciparum, Plasmodium vivax and mixed infections in the Djiboutian population by using serological tools and to identify potential determinants of the disease and hotspots of malaria transmission within the country.

Methods: The prevalence of $P$. falciparum and $P$. vivax within the districts of the capital city and the rest of the Republic of Djibouti were assessed using 13 and 2 serological markers, respectively. The relationship between the immune humeral response to $P$. falciparum and $P$. vivax and variables such as age, gender, wealth status, urbanism, educational level, distance to rivers/lakes, living area, having fever in the last month, and staying in a malaria-endemic country more than one year was estimated and analysed by questionnaires administered to 1910 Djiboutians. Multivariate ordinal logistic regression models of the immune humeral response were obtained for $P$. falciparum and P. vivax.

Results: The P. falciparum and P. vivax seroprevalence rates were 31.5\%, C195\% [29.4-33.7] and 17.5\%, Cl95\% [15.819.3], respectively. Protective effects against $P$. falciparum and $P$. vivax were female gender, educational level, and never having visited a malaria-endemic area for more than one year. For $P$. falciparum only, a protective effect was observed for not having a fever in the last month, living more than $1.5 \mathrm{~km}$ away from lakes and rivers, and younger ages.
\end{abstract}

Conclusions: This is the first study that assessed the seroprevalence of P. vivax in the Republic of Djibouti. It is necessary to improve knowledge of this pathogen in order to create an effective elimination programme. As supported by recent observations on the subject, the Republic of Djibouti has probably demonstrated a real decrease in the transmission of $P$. falciparum in the past seven years, which should encourage authorities to improve efforts toward elimination.

Keywords: Malaria, Plasmodium falciparum, Plasmodium vivax, Seroprevalence, Serological marker, Djibouti

\footnotetext{
* Correspondence: bruno.pradines@free.fr

${ }^{\dagger}$ Equal contributors

'Unité de Parasitologie, Département d'Infectiologie de Terrain, Institut de Recherche Biomédicale des Armées, Marseille, France

${ }^{2}$ Aix Marseille Université, Unité de Recherche sur les Maladies Infectieuses et

Tropicales Emergentes, UM 63, CNRS 7278, IRD 198, Inserm 1095, Marseille,

France

Full list of author information is available at the end of the article
}

\section{Biomed Central}

(c) 2012 Khaireh et al.; licensee BioMed Central Ltd. This is an Open Access article distributed under the terms of the Creative Commons Attribution License (http://creativecommons.org/licenses/by/2.0), which permits unrestricted use, distribution, and reproduction in any medium, provided the original work is properly cited. 


\section{Background}

According to the World Health Organization (WHO), approximately 3.3 billion people, nearly half of the world population, are at risk of malaria. Each year, approximately 250 million people contract the disease, and nearly one million people die. The inhabitants of the poorest countries are the most vulnerable. More than one in five infant deaths (20\%) occurring in Africa are due to malaria [1]. However, the number of Plasmodium falciparum malaria cases is declining, even in Africa. Given this situation, in the late 1990s, WHO proposed a goal of controlling the disease and achieving elimination by 2015 in areas of low transmission. Policies, international and national initiatives have proliferated to help the neediest.

Based on the results of scientific research in all areas of malaria control and because of greater knowledge of the disease and its medical and social consequences, the proposed strategy is organized into two main phases: control and disposal [2]. Among the actions undertaken on a large scale, it should be noted that the availability and distribution of ITNs and ACT, vector control through IRS, active detection of new breeding sites and their systematic destruction represent a link essential to the success of disease control before disposal is considered [3].

According to the Roll Back Malaria project, malaria primarily concerns 109 countries, but 35 countries account for $98 \%$ of malaria deaths worldwide. Only five of these countries (Nigeria, Democratic Republic of Congo, Uganda, Ethiopia and Tanzania) represent 50\% of deaths and $47 \%$ of malaria cases [4]. Among these countries, Ethiopia and Uganda share an economic community, bringing together 340 million people who are free to move to the Republic of Djibouti [5].

Formerly known to be a malaria meso- to hypoendemic country with an unstable malaria transmission profile [6-8], this country of 818,159 inhabitants declared a goal of malaria pre-elimination in 2006 [9]. Microepidemics can occur in the presence of favourable set of conditions, such as unusual rainfall (the last major outbreak occurred in 1999) [10,11]. Over the last 14 years, the transmission and the malaria cases number remained low. As a result, foreign armies present in the Republic of Djibouti have recently considered stopping their malaria chemoprophylaxis [12], as the French army did last year.

Djibouti has recently demonstrated its eligibility for the pre-elimination goal according to technical feasibility, i.e., the baseline domestic malaria transmission combined with the importation-related transmission and operational feasibility, which takes into consideration the country government status, health status and information on populations at risk [13]. These observations are in agreement with parasite genetic diversity studies $[10,11]$, and one recent work has reported a low transmission level [14].

According to WHO, malaria control requires, at a national level, the expertise and development of databases containing information about the parasites found locally and information about changes in transmission levels and the status of resistance to anti-malarials [15]. Control in the short- and medium-term is possible by developing constantly improved detection and observation tools and early care and adequate diagnoses in risk populations [15].

Therefore, serological tools are widely used to assess the transmission level and thus the prevalence of Plasmodium falciparum and Plasmodium vivax in human populations and to assess epidemiological facts of the past and present $[16,17]$. One recent work in Somaliland (the nearest neighbouring country to Djibouti with regular movements of the population in both directions) has used serological tools to assess the prevalence of $P$. falciparum and P. vivax [18-20].

Starting from this observation, it was necessary to perform a similar survey in the Republic of Djibouti. Because most of the previous studies have primarily concerned $P$. falciparum malaria, it was also necessary to study $P$. vivax malaria and mixed infections to gather enough information for elimination [3].

The aim of the present study was to evaluate the prevalence rate of $P$. falciparum, $P$. vivax and mixed infections in the Djiboutian population by using serological tools and to identify potential determinants of hot spots of malaria infection and transmission within the country.

\section{Methods}

\section{Sera samples}

The prevalence rate of $P$. falciparum and $P$. vivax infections among adults aged 15-54 years living in the Republic of Djibouti was estimated using a anonymous non-correlated cluster sampling method between the $24^{\text {th }}$ and the $31^{\text {th }}$ of March 2002. In brief, 30 clusters were investigated in the city of Djibouti, and 25 clusters in the other districts of the country. The clusters were randomly selected proportionally to the population size according to the list of quarters used by the National Direction of Statistics in the city of Djibouti and the list of the towns used by the expanded programme of immunization in the other districts. In each selected site, a starting household was randomly selected, and the next nearest households were investigated until a total of 44 resident adults per cluster in the city of Djibouti or 35 resident adults per cluster in the other districts were obtained. A total of 1,910 blood samples were collected anonymously in accordance 
with the recommendations of the Djiboutian Ministry of Health, who gave the ethics clearance for the present study. Blood samples were stored at $4{ }^{\circ} \mathrm{C}$ until separation of plasma by centrifugation (less than 24 hours after collection) and freezing. Thirty sera samples from French adults who had never been to malaria-endemic countries were used as unexposed negative controls. For the seropositivity threshold, the means and standard deviations (SDs) of the antibody intensity of the negative control group for all antigens were estimated. The lower limit of positivity for each antibody was taken as the mean +3 SD of the negative control group values and corresponded to a mean fluorescence intensity (MFI) of 1,000. For P. falciparum, a sample was considered to be positive if the reactivity to at least two different plasmodial antigens was $>1,000$ MFI. For P. vivax, a sample was considered to be positive if the reactivity to PvMSP1-19 or to PvMSP1-42 was > 1,000 MFI.

\section{Peptides and proteins}

Eleven Peptides (Lsa1-41, Lsa1-J, Lsa3-NR2, Glurp, GlurpP3, Salsa1, Salsa2, Trap1, Starp-R, CS (NANP) and SR11.1) were synthesized with an added N-terminal cysteine residue and covalently coupled with BSA (bovine serum albumin, Sigma-Aldrich, St. Louis, USA) by Genpep (Ales, France) and stored in aliquots at $-20{ }^{\circ} \mathrm{C}$. $P$. falciparum merozoite surface protein $1-19\left(\mathrm{MSP}_{19}\right)$ and apical membrane antigen 1 (AMA1) were obtained using procedures previously described [14]. For P. vivax, MSP1 $_{19}$ proteins were produced in a baculovirus [21] and $\mathrm{MSP}_{42}$ as described elsewhere [19].

\section{Bead-based assay}

Peptides and proteins were coupled to beads as described by Ambrosino et al. [22], and an optimal concentration of $0.3 \mathrm{nmol}$ was used for each antigen. Furthermore, BSA coated beads were included as a background control. Ag-coated beads were resuspended by vortexing and sonication for 5 minutes and were diluted in equal volumes of PBS and MFIA (Multiplexed Fluorescence ImmunoAssay) diluent (Charles River Laboratories Inc, MA, USA) to a final concentration of 80 beads/ $\mu \mathrm{l}$ per peptide. The $1.2-\mu \mathrm{m}$ filter-bottom 96 -well microtiterplates (MSBVS 1210, Millipore, MA, USA) were rewetted with washing buffer $(0.15 \%$ Tween 20 in PBS 7.4) using a vacuum manifold (Millipore). Fifty microliters of beads and sera (diluted 1:100 in equal volumes of PBS and MFIA diluents) were added to each well. Plates were incubated at room temperature in the dark for $1 \mathrm{~h}$ with shaking at $600 \mathrm{rpm}$. After incubation, plates were washed eight times with $200 \mu \mathrm{l}$ of washing buffer, then $100 \mu \mathrm{l}$ of the secondary Ab (R-phycoerythrin $\mathrm{F}(\mathrm{ab}) 2$ fragment of goat anti-human IgG, (Interchim,
Montluçon, France), diluted 1:500, was added to each well. After $30 \mathrm{~min}$ of incubation in the dark at room temperature with shaking, plates were washed as described previously. Beads were resuspended in $100 \mu \mathrm{l}$ of a solution of 5\% BSA-PBS, $\mathrm{pH} 7.4$ and analysed on Luminex system. The system was set to read a minimum of 100 beads per spectral address, and the results were expressed as MFI.

\section{Data collection}

During the cross-sectional study between the $24^{\text {th }}$ and the $31^{\text {th }}$ March 2002, self-administered questionnaires containing several items were filled out by Djiboutian inhabitants and validated by a member of the research team. Different types of independent variables were collected: the living area (the city of Djibouti or the rest of the country), the type of living area (urban or rural), having stayed in a malaria-endemic country for more than one year (yes or no), having had a fever during the last month before the study (yes or no), the utilization of bed nets (often to always and rarely to never), gender (male or female), schooling status (schooled or never schooled), educational level (never schooled, primary school, secondary school, high school or university), wealth (poor $=$ less than 65,000 Djiboutian Francs per home and rich $=$ more than 65,000 Djiboutian Francs per home), and age.

A Geographic Information System was built in ArcGIS 9.2 (Environmental Research Systems Institute, Redlands, CA). The layers were added as follows: i) map of inland water in Djibouti and the neighbouring countries (data from Digital Chart of the World, accessed through DIVA-GIS [23] and ii) 60 points corresponding to the sampling locations. At every point, the Euclidian distance to the first pixel of water was computed. This enabled the creation of a geographical independent variable, the distance of a cluster to a river or a lake $(\leq 1.5 \mathrm{Km}$ or $>1.5 \mathrm{Km})$.

\section{Statistical methods}

Data were recorded using Excel and were checked for consistency before statistical analysis using $\mathrm{R}$ software (version 2.10.1) or STATA software (version 11). The seropositivity to $P$. falciparum antigens, $P$. vivax antigens or both of them (mixed infection) were analysed as a dependant variable according to individual and cluster characteristics using a random effect mixed logistic regression model. The model was designed to take into account the intracluster correlations that could exist due to the sampling design (cluster effect as random effect). The logistic model was also adjusted using a generalized estimating equations (GEE) approach. Random effect and GEE regression models allow the estimation of cluster-specific and population- 
averaged effects, respectively [24]. First, a descriptive analysis of the independent variables was performed. A bivariate analysis was then conducted by entering each independent variable in a logistic regression model, and all the results were presented in Additional files 1, 2, 3, 4, 5 and 6. Variables were retained for the multivariate analysis if their effect had a p-value less than 0.25 [25]. A backward stepwise selection procedure was applied to retain the significant $(\mathrm{p}<0.05)$ independent variables and their interactions in the final model. The statistical quality of the final model was assessed by looking at the adequacy between observed and predicted prevalence rates.

As the immune response to several $P$. falciparum or $P$. vivax antigens could be quantified by MFI, another ordinal dependant variable in four classes was created: the level of immune response to $P$. falciparum antigens $(\mathrm{L} 0=$ seronegativity $\mathrm{MFI}<1000, \mathrm{~L} 1=1000 \leq \mathrm{MFI}<3800$, $\mathrm{L} 2=3800 \leq \mathrm{MFI}<8000$, and $\mathrm{L} 3=\mathrm{MFI} \geq 8000)$ and $P$. vivax antigens $(\mathrm{L} 0=$ seronegativity $\mathrm{MFI}<1000, \mathrm{~L} 1=$ $1000 \leq \mathrm{MFI}<2000, \mathrm{~L} 2=2000 \leq \mathrm{MFI}<10000$ and $\mathrm{L} 3=$ MFI $\geq 10000$ ). The same type of analysis was applied to this dependent variable as described above for the seropositivity status, using the "svy" command of STATA (i.e., using the linearized variance estimator based on a first-order Taylor series linear approximation) to take into account the cluster effect.
The results of the bivariate Bayesian ordinal multinomial regression analysis are presented in Additional files 7 and 8.

\section{Results}

\section{Plasmodium falciparum seroprevalence}

The serological analysis showed that $25.90 \%$ of sera were positive for at least two of the following $11 \mathrm{P}$. falciparum peptides: Lsa1-41, Lsa1-J, Lsa3-NR2, Glurp, GlurpP3, Salsa1, Salsa2, Trap1, Starp-R, CS (NANP) and SR11.1. The proportion of sera that were positive for both and at least one of the two recombinant falciparum antigens, i.e., PfMSP1 and PfAMA1, were $13.24 \%$ and $29.98 \%$, respectively. By taking into account the immune humeral response to at least two different peptides or recombinant proteins of the $13 P$. falciparum antigens used in this study, the seropositivity rate to $P$. falciparum infection was 31.5\% (602/1910 Djiboutian people), CI95\% (29.4-33.7).

Considering the potential determinants of the P. falciparum malaria infection, according to the results of the multivariate logistic regression analysis (Table 1), some factors were significantly and independently statistically associated with a lower risk of being seropositive for P. falciparum:

- The gender (female gender).

Table 1 Multivariate logistic regression analysis of $\boldsymbol{P}$. falciparum infection's seroprevalence

\begin{tabular}{|c|c|c|c|c|c|c|}
\hline & \multirow[t]{2}{*}{$\mathbf{N}$} & \multirow[t]{2}{*}{$\mathbf{P}$} & \multirow[t]{2}{*}{$\%(95 \% \mathrm{Cl})$} & \multicolumn{3}{|c|}{ RE } \\
\hline & & & & COR (CI95\%) & aOR (CI95\%) & $\mathrm{p}$-value \\
\hline \multicolumn{7}{|l|}{ Gender } \\
\hline Male & 742 & 256 & $34.5(31.1-38.0)$ & 1 & 1 & 0.0008 \\
\hline Female & 1168 & 346 & $29.6(27.0-32.3)$ & $0.78(0.63-0.96)$ & $0.68(0.55-0.85)$ & \\
\hline \multicolumn{7}{|l|}{ Educational level } \\
\hline No school & 1244 & 448 & $36.0(33.3-38.6)$ & 1 & 1 & 0.033 \\
\hline Primary & 410 & 106 & $25.9(21.7-30.4)$ & $0.65(0.50-0.84)$ & $0.66(0.50-0.87)$ & $1.6 \times 10^{-5}$ \\
\hline Secondary, high school or University & 256 & 48 & $18.8(14.2-24.1)$ & $0.45(0.32-0.64)$ & $0.45(0.31-0.64)$ & \\
\hline \multicolumn{7}{|c|}{ Staying in a malaria endemic country more than one year } \\
\hline Yes & 167 & 70 & $41.9(34.3-49.8)$ & 1 & 1 & 0.0005 \\
\hline No & 1743 & 532 & $30.5(28.4-32.7)$ & $0.50(0.35-0.72)$ & $0.52(0.36-0.75)$ & \\
\hline \multicolumn{7}{|l|}{ Having fever during the last month } \\
\hline Yes & 435 & 175 & $40.2(35.6-45.0)$ & 1 & 1 & 0.0003 \\
\hline No & 1475 & 427 & $28.9(26.8-31.5)$ & $0.61(0.47-0.78)$ & $0.63(0.49-0.81)$ & \\
\hline \multicolumn{7}{|l|}{ Age (Years) } \\
\hline [15-40] & 1360 & 401 & $29.5(27.1-32.0)$ & 1 & 1 & 0.0346 \\
\hline$[40-55]$ & 550 & 201 & $36.5(32.5-40.7)$ & $1.42(1.14-1.77)$ & $1.28(1.02-1.61)$ & \\
\hline \multicolumn{7}{|l|}{ Distance to rivers $(\mathrm{Km})$} \\
\hline$>1.5 \mathrm{Km}$ & 1279 & 364 & $28.5(26.0-31.0)$ & 1 & 1 & 0.0671 \\
\hline$\leq 1.5 \mathrm{Km}$ & 631 & 238 & $37.7(33.9-41.6)$ & $1.48(0.99-2.21)$ & $1.44(0.97-2.14)$ & \\
\hline
\end{tabular}

$\mathrm{N}=$ number; $\mathrm{P}=$ seropositivity to $\mathrm{P}$. falciparum; $\mathrm{RE}=$ Random effect; $\mathrm{COR}=$ Crude Odd ratio; aOR = Adjusted Odd ratio; $\mathrm{Cl} 95 \%=$ Confident interval $95 \%$. 
Table 2 Multivariate logistic regression analysis of $P$. vivax infection's seroprevalence

\begin{tabular}{|c|c|c|c|c|c|c|}
\hline & \multirow[t]{2}{*}{$\mathbf{N}$} & \multirow[t]{2}{*}{$P$} & \multirow[t]{2}{*}{$\%(95 \% \mathrm{Cl})$} & \multicolumn{3}{|c|}{ RE } \\
\hline & & & & cOR (Cl95\%) & aOR (Cl95\%) & $p$-value \\
\hline \multicolumn{7}{|l|}{ Gender } \\
\hline Male & 742 & 147 & $19.8(17.0-22.9)$ & 1 & 1 & \\
\hline Female & 1168 & 187 & $16.0(14.0-18.2)$ & $0.75(0.59-0.97)$ & $0.72(0.56-0.93)$ & 0.0106 \\
\hline \multicolumn{7}{|l|}{ Schooling } \\
\hline Schooled & 666 & 97 & $14.6(10.6-15.9)$ & 1 & 1 & \\
\hline Never schooled & 1244 & 237 & $19.1(16.9-21.3)$ & $1.32(1.01-1.73)$ & $1.40(1.06-1.85)$ & 0.0163 \\
\hline \multicolumn{7}{|c|}{$\begin{array}{l}\text { Staying in a malaria endemic } \\
\text { country more than one year }\end{array}$} \\
\hline Yes & 167 & 45 & $26.9(20.4-34.3)$ & 1 & 1 & \\
\hline No & 1743 & 289 & $16.6(14.9-18.4)$ & $0.51(0.34-0.75)$ & $0.52(0.35-0.77)$ & 0.0012 \\
\hline
\end{tabular}

$\mathrm{N}=$ number; $\mathrm{P}=$ seropositivity to $\mathrm{P}$. vivax; $\mathrm{RE}=$ Random effect; $\mathrm{cOR}=$ Crude odd ratio; aOR = Adjusted Odd ratio; $\mathrm{Cl} 95 \%=\mathrm{Confident}$ interval $95 \%$.

- The educational level (primary school, secondary school and higher levels).

- Never having visited a malaria-endemic area for more than one year.

- Not having had a fever during the last month before the study.

In contrast, only one risk factor for seropositivity for P. falciparum was identified: older age (40 years to 55 years). There was a non-significant association of living near lakes and rivers $(\leq 1.5 \mathrm{Km})$ with a higher risk of seropositivity.

\section{Plasmodium vivax seroprevalence}

By taking into account the reactivity against $\mathrm{PvMSP}_{42}$

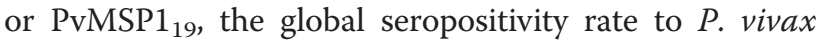
was $17.5 \%$ (334/1910 Djiboutian people), CI95\% (15.819.3). Considering the potential determinants of the P. vivax malaria infection, according to the results of the multivariate logistic regression analysis (Table 2), some factors were significantly and independently statistically associated with a lower risk of being seropositive for P. vivax:

- The gender (female gender).

Table 3 Multivariate logistic regression analysis of $P$. falciparum and vivax mixed infection's seroprevalence

\begin{tabular}{|c|c|c|c|c|c|c|}
\hline & \multirow[t]{2}{*}{$N$} & \multirow[t]{2}{*}{$\mathbf{P}$} & \multirow[t]{2}{*}{$\%(95 \% \mathrm{Cl})$} & \multicolumn{3}{|c|}{ RE } \\
\hline & & & & cOR (Cl95\%) & aOR (Cl95\%) & p-value \\
\hline \multicolumn{7}{|l|}{ Type of living area } \\
\hline Rural & 553 & 43 & $7.8(5.7-10.3)$ & 1 & 1 & 0.0477 \\
\hline Urban & 1357 & 152 & $11.2(9.6-13.0)$ & $1.52(0.83-2.78)$ & $1.77(1.01-3.11)$ & \\
\hline \multicolumn{7}{|l|}{ Gender } \\
\hline Male & 742 & 91 & $12.3(10.0-14.8)$ & 1 & 1 & 0.0006 \\
\hline Female & 1168 & 104 & $8.9(7.3-10.7)$ & $0.65(0.47-0.90)$ & $0.56(0.40-0.78)$ & \\
\hline \multicolumn{7}{|l|}{ Educational level } \\
\hline Schooled & 666 & 44 & $6.6(4.8-8.8)$ & 1 & 1 & 0.004 \\
\hline Never Schooled & 1244 & 151 & $12.1(10.4-14.1)$ & $1.81(1.24-2.63)$ & $2.04(1.38-3.02)$ & \\
\hline \multicolumn{7}{|c|}{ Staying in a malaria endemic country more than one year } \\
\hline Yes & 167 & 31 & $18.6(13.0-25.3)$ & 1 & 1 & 0.0012 \\
\hline No & 1743 & 164 & $9.4(8.1-10.9)$ & $0.39(0.24-0.64)$ & $0.45(0.27-0.73)$ & \\
\hline \multicolumn{7}{|c|}{ Having fever during the last month } \\
\hline Yes & 435 & 65 & $14.9(11.7-18.6)$ & 1 & 1 & 0.0011 \\
\hline No & 1475 & 130 & $8.8(7.4-10.4)$ & $0.54(0.37-0.77)$ & $0.54(0.38-0.78)$ & \\
\hline \multicolumn{7}{|c|}{ Distance to rivers or lakes $(\mathrm{Km})$} \\
\hline$>1.5 \mathrm{Km}$ & 1210 & 97 & $8.0(6.5-9.7)$ & 1 & 1 & 0.0190 \\
\hline$\leq 1.5 \mathrm{Km}$ & 700 & 98 & 14.0 (11.5-16.8) & $1.83(1.07-3.13)$ & $1.83(1.10-3.04)$ & \\
\hline
\end{tabular}

$\mathrm{N}=$ number; $\mathrm{P}=$ seropositivity to $\mathrm{P}$. falciparum and $\mathrm{P}$. vivax; $\mathrm{RE}=$ Random effect; $\mathrm{COR}=$ Crude Odd ratio; aOR = Adjusted Odd ratio; $\mathrm{Cl} 95 \%=\mathrm{Confident}$ interval $95 \%$. 
- Never having visited a malaria-endemic country for more than one year.

Having no schooling was significantly and independently statistically associated with a higher risk of being seropositive for $P$. vivax infection.

\section{Mixed infection seroprevalence}

The global seropositivity rate of mixed infection was 10.2\% (195/1910 Djiboutian people), CI95\% (8.9-11.7). The results of the multivariate logistic regression analysis for predicting a mixed infection (Table 3), i.e., seropositivity to serological markers of both $P$. falciparum and $P$. vivax, showed that some variables were significantly and independently statistically associated with a lower risk of being seropositive for mixed infection:

- The gender (female gender).

- Never having visited a malaria-endemic country for more than one year.

- Not having had a fever during the last month before the study.

Some factors were significantly and independently statistically associated with a higher risk of being seropositive for mixed infection:

- The type of living area (urban).

- The educational level (never schooled).

- The distance to rivers or lakes $(\leq 1.5 \mathrm{Km})$.

\section{Bayesian ordinal multinomial logistic regression for the level of response to $P$. falciparum antigens}

The proportions of $P$. falciparum seropositives to the different peptides and recombinant proteins from the different L-groups $(\mathrm{L} 0=$ seronegativity $\mathrm{MFI}<1,000, \quad \mathrm{~L} 1=$ $1,000 \leq \mathrm{MFI}<3,800, \mathrm{~L} 2=3,800 \leq \mathrm{MFI}<8,000$, and $\mathrm{L} 3=$ MFI $\geq 8,000$ ) were illustrated in Figure 1 . The distribution of corrected MFI values against the $P$. falciparum antigens in the L1, L2 and L3 groups was presented in Figure 2.

According to the results of the Bayesian ordinal multinomial logistic regression analysis (Table 4), some factors were significantly and independently statistically associated with a lower risk of having a high level of immune humeral response to $P$. falciparum antigens:

- The gender (female gender).

- The educational level (primary school, secondary, high school or university).

- Never having visited a malaria-endemic country for more than one year.

- Not having had a fever during the last month before the study.

- Rarely to never used bed nets.

In contrast, only one risk factor was significantly and independently associated statistically with a risk of having a high level of immune humeral response to $P$. falciparum antigens:

- The distance to rivers $(\leq 1.5 \mathrm{Km})$.

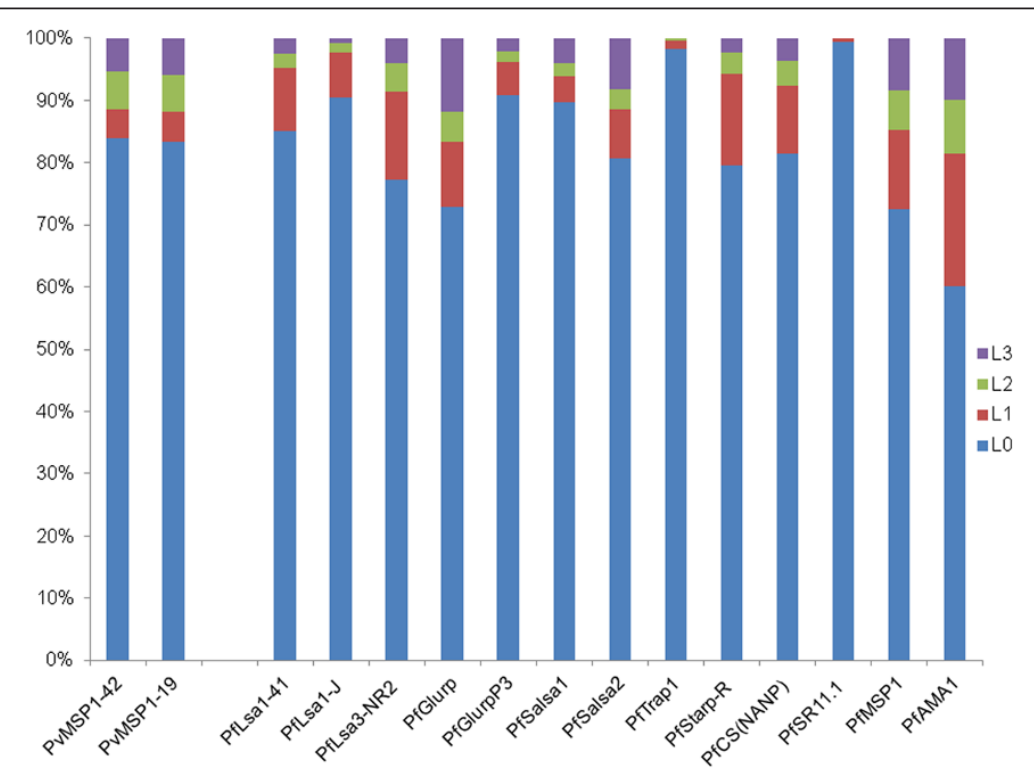

Figure 1 Proportions of $P$. falciparum and $P$. vivax seropositives to the different peptides and recombinant proteins from the different L-groups (for $P$. falciparum, $\mathrm{L} 0=$ seronegativity $\mathrm{MFI}<1000, \mathrm{~L} 1=1000 \leq \mathrm{MFI}<3800, \mathrm{~L} 2=3800 \leq \mathrm{MFI}<8000$, and $\mathrm{L} 3=\mathrm{MFI} \geq 8000$; for $P$. vivax, $\mathrm{L} 0=$ seronegativity $\mathrm{MFI}<1000, \mathrm{~L} 1=1000 \leq \mathrm{MFI}<2000, \mathrm{~L} 2=2000 \leq \mathrm{MFI}<10000$ and $\mathrm{L} 3=\mathrm{MFI} \geq 10000$ ). 


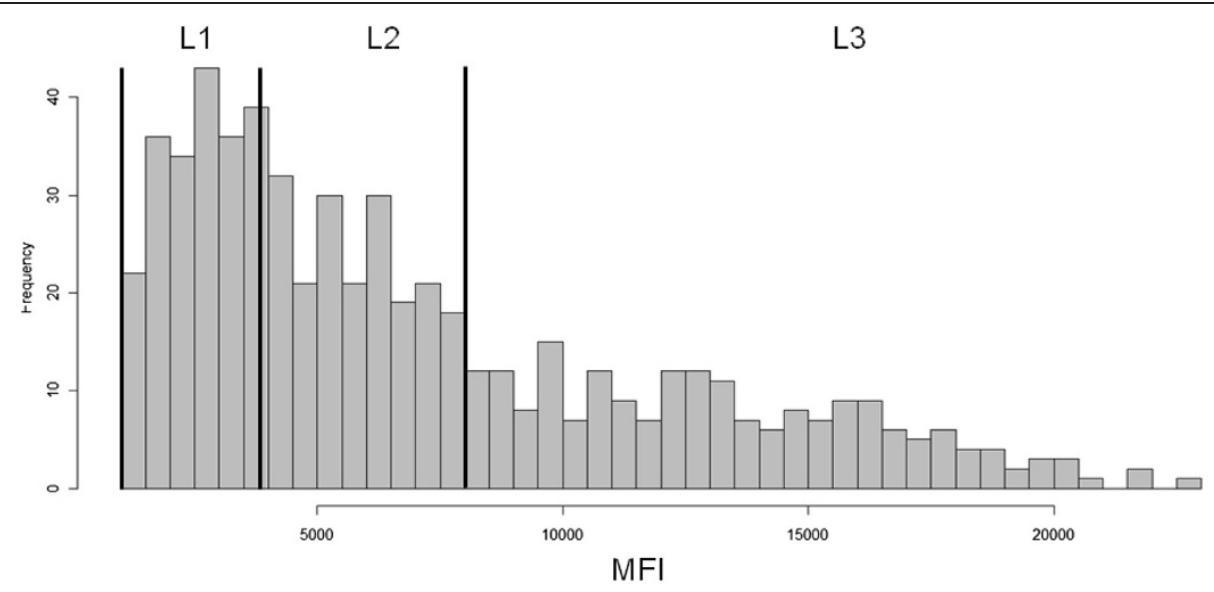

Figure 2 Distribution of corrected MFI values against the $P$. falciparum antigens in the L1, L2 and L3 groups.

Bayesian ordinal multinomial logistic regression for the level of response to $P$. vivax antigens

The proportions of $P$. vivax seropositives to the different recombinant proteins from the different L-groups $(\mathrm{LO}=$ seronegativity $\mathrm{MFI}<1,000, \mathrm{~L} 1=1,000 \leq \mathrm{MFI}<2,000$, L2 $=2,000 \leq \mathrm{MFI}<10,000$ and $\mathrm{L} 3=\mathrm{MFI} \geq 10,000)$ were illustrated in Figure 1. The distribution of corrected MFI values against the $P$. vivax antigens in the L1, L2 and L3 groups was presented in Figure 3. According to the results of the Bayesian ordinal multinomial logistic regression analysis (Table 5), some factors were significantly and independently statistically associated with a lower risk of having a high level of immune humeral response to $P$. vivax antigens:

- The gender (female gender).

Table 4 Multivariate ordinal logistic regression analysis of serological response to $P$. falciparum antigens

\begin{tabular}{|c|c|c|c|c|c|c|c|c|}
\hline & \multirow[t]{2}{*}{$\mathbf{N}$} & \multicolumn{4}{|c|}{$\mathbf{P}$} & \multicolumn{3}{|c|}{ RE } \\
\hline & & L1 & L2 & L3 & Total & COR (CI95\%) & aOR (CI95\%) & p-value \\
\hline \multicolumn{9}{|l|}{ Gender } \\
\hline Male & 742 & 80 & 79 & 97 & 256 & 1 & 1 & 0.0008 \\
\hline Female & 1168 & 116 & 127 & 103 & 346 & $0.78(0.65-0.95)$ & $0.66(0.54-0.81)$ & \\
\hline \multicolumn{9}{|l|}{ Educational level } \\
\hline No school & 1244 & 141 & 145 & 162 & 448 & 1 & 1 & \\
\hline Primary & 410 & 40 & 39 & 27 & 106 & $0.61(0.47-0.77)$ & $0.60(0.47-0.77)$ & \\
\hline Secondary, high school or University & 256 & 15 & 22 & 11 & 48 & $0.41(0.30-0.57)$ & $0.39(0.28-0.55)$ & \\
\hline \multicolumn{9}{|c|}{ Staying in a malaria endemic country more than one year } \\
\hline Yes & 167 & 19 & 18 & 33 & 70 & 1 & 1 & 0.0019 \\
\hline No & 1743 & 177 & 188 & 167 & 532 & $0.57(0.42-0.78)$ & $0.55(0.40-0.76)$ & \\
\hline \multicolumn{9}{|l|}{ Having fever during the last month } \\
\hline Yes & 435 & 48 & 58 & 69 & 175 & 1 & 1 & 0.0002 \\
\hline No & 1475 & 148 & 148 & 131 & 427 & $0.59(0.47-0.72)$ & $0.59(0.47-0.73)$ & \\
\hline \multicolumn{9}{|l|}{ Distance to rivers and lakes $(\mathrm{Km})$} \\
\hline$>1.5 \mathrm{Km}$ & 1210 & 124 & 121 & 101 & 346 & 1 & 1 & 0.0007 \\
\hline$\leq 1.5 \mathrm{Km}$ & 700 & 72 & 85 & 99 & 256 & $1.49(1.23-1.81)$ & $1.53(1.25-1.87)$ & \\
\hline \multicolumn{9}{|l|}{ Bed nets utilization } \\
\hline Often to Always & 769 & 82 & 90 & 107 & 279 & 1 & 1 & 0.0007 \\
\hline Rarely to Never & 1141 & 114 & 116 & 93 & 323 & $0.67(0.56-0.81)$ & $0.61(0.50-0.74)$ & \\
\hline
\end{tabular}

$\mathrm{N}=$ number; $\mathrm{P}=$ seropositivity to $P$. falciparum; $\mathrm{L}=$ level of intensity of immunological response (seropositivity to $P$. falciparum antigens) measured in $\mathrm{MFI}$ with 3 levels: $1,2,3$ corresponding respectively to $1000 \leq \mathrm{MFI}<3800,3800 \leq \mathrm{MFI}<8000, \mathrm{MFI} \geq 8000$. The level L0 is not shown here as it's corresponding to value of MFI $<1000$ considered as negative reaction. $\mathrm{RE}=$ Random effect; $\mathrm{cOR}=$ Crude Odd ratio; aOR = Adjusted Odd ratio; Cl95\% $=\mathrm{Confident}$ interval $95 \%$. 


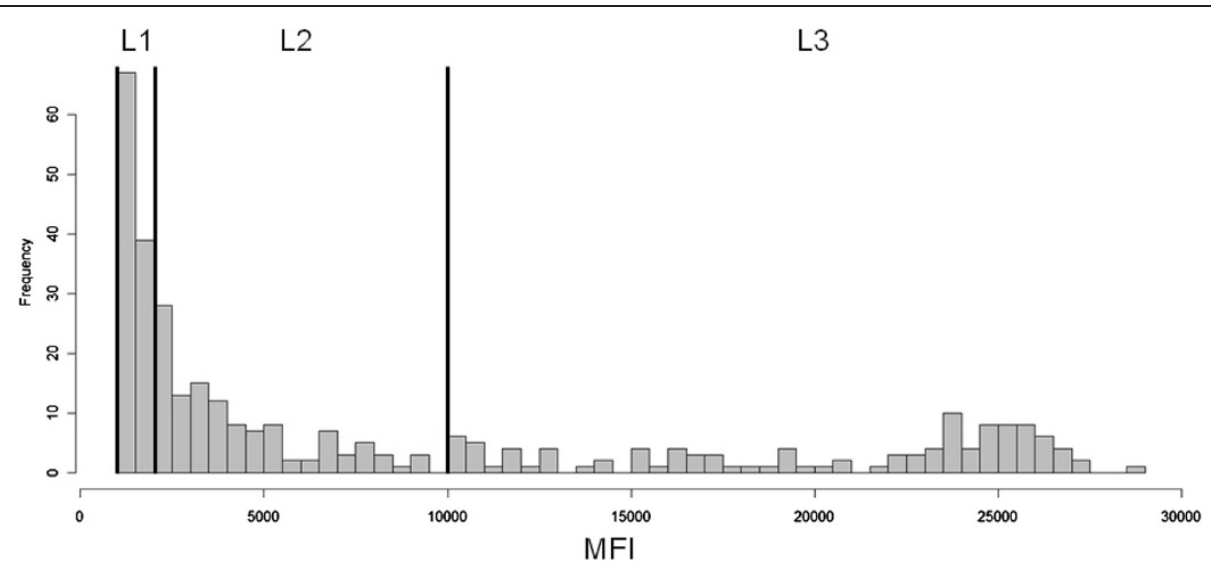

Figure 3 Distribution of corrected MFI values against the $P$. vivax antigens in the L1, L2 and L3 groups.

- Never having visited a malaria-endemic country for more than one year.

- Not having had a fever during the last month before the study.

Two risk factors were significantly and independently statistically associated with a risk of having a high level of immune humeral response to $P$. vivax antigens:

- The distance to rivers $(\leq 1.5 \mathrm{Km})$.

- The educational level (never schooled).

\section{Geographical repartition}

The different clusters of $P$. falciparum and $P$. vivax seroprevalence were presented in Figures 4, 5, 6, and 7 and in Additional file 9. For P. falciparum, the city of Djibouti showed a clustering of low and medium prevalence areas on both sides of the Ambouli wadi. A hotspot was observed in Arhiba, in which more than half of the population (56.4\%) (Additional file 10) was seropositive for P. falciparum. A mean tendency was observed in the upper town (i.e., Quarters 1 to 15), which globally showed a decreasing prevalence when the distance to

Table 5 Multivariate ordinal logistic regression analysis of the serological response to $P$. vivax antigens

\begin{tabular}{|c|c|c|c|c|c|c|c|c|}
\hline & \multirow[t]{2}{*}{$\mathbf{N}$} & \multicolumn{4}{|c|}{$\mathbf{P}$} & \multicolumn{3}{|c|}{ RE } \\
\hline & & L1 & L2 & L3 & Total & COR (Cl95\%) & aOR (Cl95\%) & p-value \\
\hline \multicolumn{9}{|l|}{ Gender } \\
\hline Male & 742 & 51 & 52 & 44 & 147 & 1 & 1 & 0.0286 \\
\hline Female & 1168 & 54 & 65 & 68 & 187 & $0.79(0.62-1.00)$ & $0.74(0.58-0.94)$ & \\
\hline \multicolumn{9}{|c|}{ Educational level } \\
\hline Schooled & 666 & 37 & 35 & 25 & 97 & 1 & 1 & 0.0168 \\
\hline Non Schooled & 1244 & 68 & 82 & 87 & 237 & $1.41(1.09-1.82)$ & $1.44(1.11-1.87)$ & \\
\hline \multicolumn{9}{|c|}{ Staying in a malaria endemic country more than one year } \\
\hline Yes & 167 & 9 & 18 & 18 & 45 & 1 & 1 & 0.0042 \\
\hline No & 1743 & 96 & 99 & 94 & 289 & $0.52(0.37-0.75)$ & $0.53(0.37-0.76)$ & \\
\hline \multicolumn{9}{|c|}{ Having fever during the last month } \\
\hline Yes & 435 & 25 & 29 & 36 & 90 & 1 & 1 & 0.0447 \\
\hline No & 1475 & 80 & 88 & 76 & 244 & $0.75(0.57-0.97)$ & $0.74(0.56-0.97)$ & \\
\hline \multicolumn{9}{|c|}{ Distance to rivers and lakes $(\mathrm{Km})$} \\
\hline$>1.5 \mathrm{Km}$ & 1210 & 66 & 65 & 60 & 191 & 1 & 1 & 0.0301 \\
\hline$\leq 1.5 \mathrm{Km}$ & 700 & 39 & 52 & 52 & 143 & $1.39(1.09-1.76)$ & $1.35(0.56-0.97)$ & \\
\hline
\end{tabular}

$\mathrm{N}=$ number; $\mathrm{P}=$ seropositivity to $P$. vivax; $\mathrm{L}=$ level of intensity of immunological response (seropositivity to $P$. vivax antigens) measured in MFI with 3 levels: $1,2,3$ corresponding respectively to $1000 \leq \mathrm{MFI}<2000,2000 \leq \mathrm{MFI}<10000$ and $\mathrm{MFI} \geq 10000$. The level Lo is not shown here as it's corresponding to value of MFI $<1000$ considered as negative reaction. $\mathrm{RE}=$ Random effect; $\mathrm{cOR}=$ Crude Odd ratio; aOR = Adjusted Odd ratio; $\mathrm{Cl} 95 \%=\mathrm{Confident}$ interval $95 \%$. 


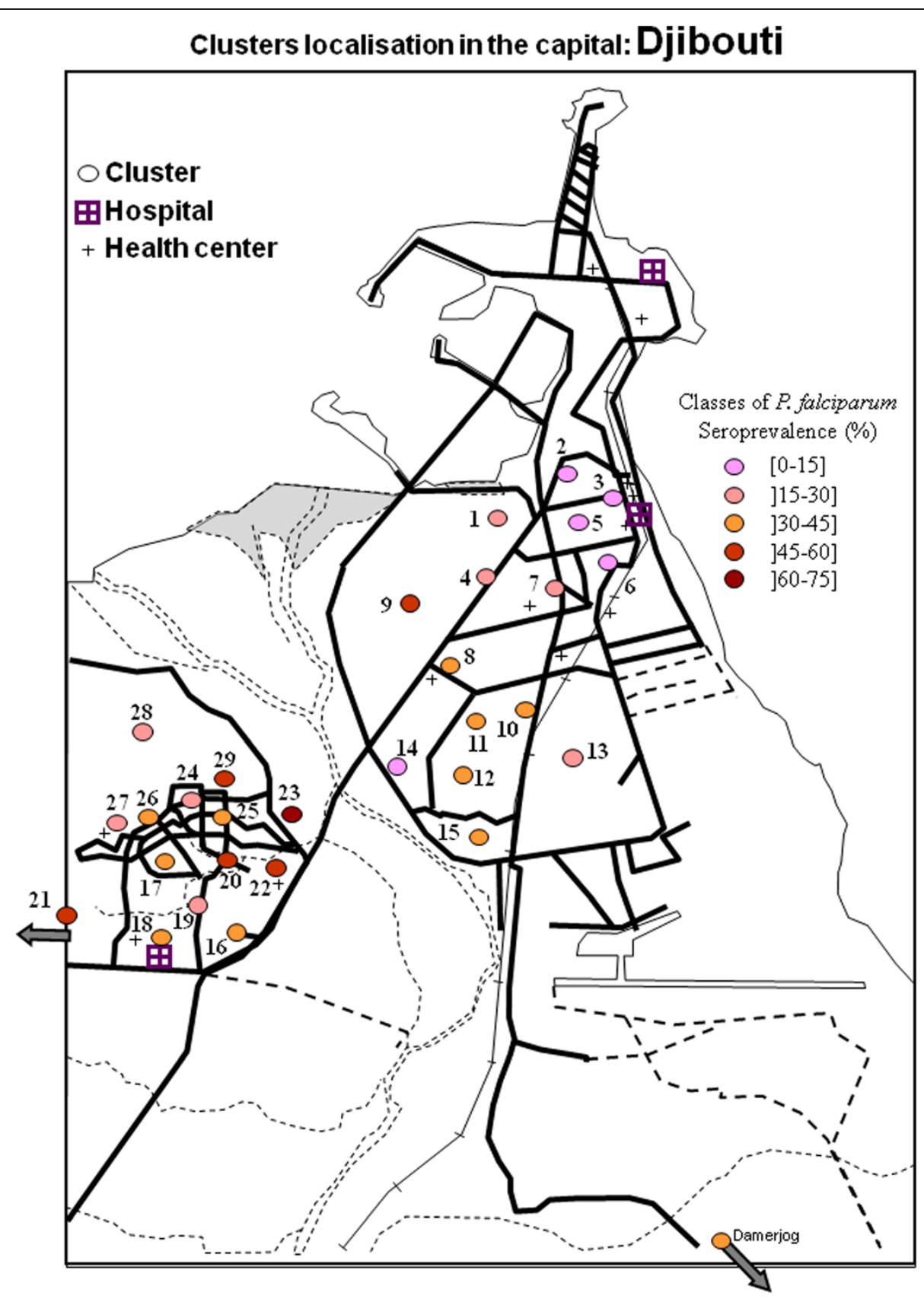

Figure 4 Map of clusters of Plasmodium falciparum seroprevalence in the capital of the republic of Djibouti.

Ambouli wadi increased. This tendency was also observed in the lower town, i.e., the other side of the Ambouli wadi quarter, with 4 hotspots (Balbala 2, PK12, Balbala 3, and North of Wahle Daba) that had similar prevalence to Arhiba. The most prevalent cluster in the entire country was Balbala 4, in which almost two in three persons (67.5\%) were seropositive for $P$. falciparum.

In the rest of the country (Additional file 11), the 2 regions in the north (Tadjourah and Obock) exhibited a low prevalence, except for Balho, in which more than one in three persons were seropositive for P. falciparum. The situation in the South was more concerning, as 3 seropositivity hotspots were observed in Dagguirou (46.9\%), Tammiro (64.7\%) and As-Eyla (64.7\%) in the Region of Dikhil, and 2 seropositivity hotspots were observed in Ali-Sabieh1 (52\%) and Ali-Sabieh 3 (45.5\%), the capital city of the Region of Ali-Sabieh.

Considering the prevalence of $P$. vivax, in Djibouti city, on both sides of Ambouli wadi, an increase in the 


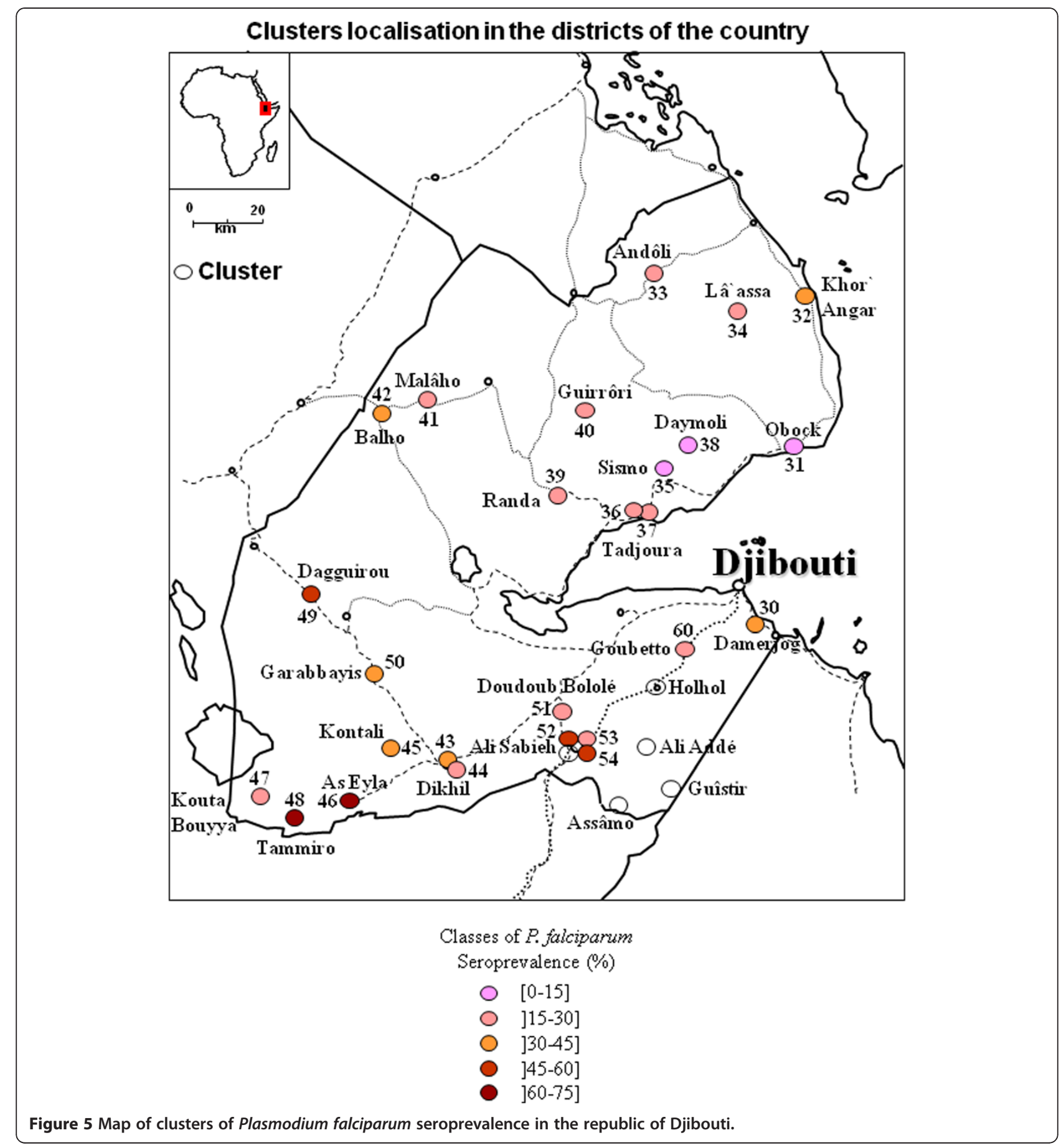

distance between quarters and the wadi was associated with a decrease in prevalence rates, as was true for $P$. falciparum. In the upper town, the only hotspot was in Arhiba, with a $33.3 \%$ seroprevalence. In the lower town, two hotspots were observed in Balbala 4 and north of the Wahle Daba, with $35 \%$ and $44.4 \%$ seroprevalence, respectively.

Of the northern regions, Obock and Tadjourah, the seroprevalence rates in some localities were $20 \%$ to $30 \%$, such as in Malâho, La'Assa (Obock Region) and the regional capital Tadjourah (Tadjourah Region). In southern regions, the seroprevalence rates were between 20\% and $30 \%$, such as in Dagguirou, Garabayis (or Gour'abouss) and As-Eyla for the Dikhil region and Doudoub Balaleh for the Ali-Sabieh region. Hotspots were observed in Tammiro, with a $32.4 \%$ seroprevalence rate (in the region of Dikhil), and in Ali-Sabieh 1, with a $40 \%$ seroprevalence rate (the capital of Ali-Sabieh's region). 


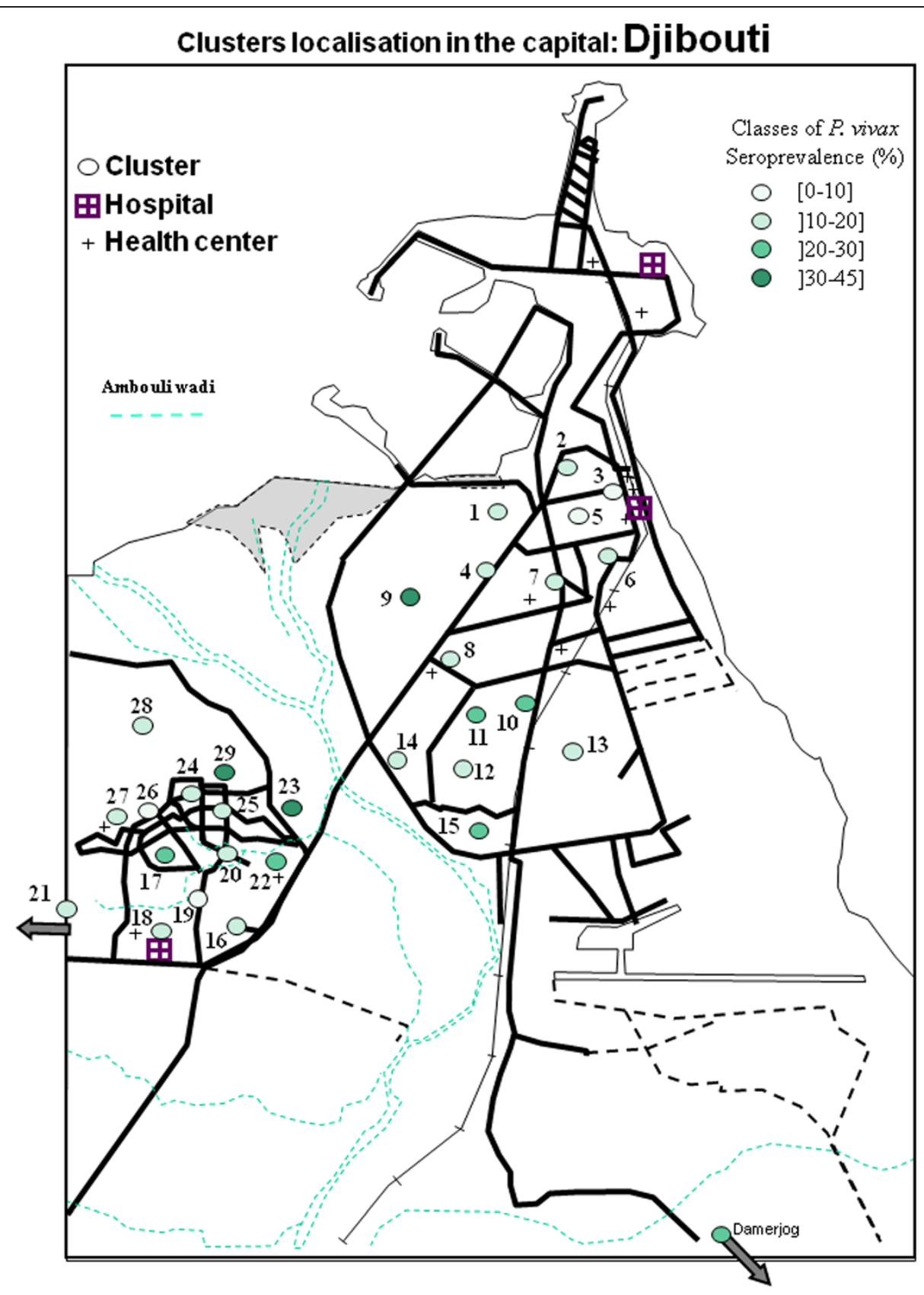

Figure 6 Map of clusters of Plasmodium vivax seroprevalence in the capital of the republic of Djibouti.

\section{Discussion}

The present study was the first to analyse the $P$. vivax seroprevalence rate in the Republic of Djibouti. Supplemental information on the $P$. falciparum situation in 2002 was also highlighted.

\section{Serological tools for $P$. falciparum infection}

The use of different antigenic peptides was dictated by the fact that in countries where malaria transmission occurs, the results of serology may be ambiguous due to cross reactions with other parasitic infections, such as toxoplasmosis [26]. Thus, by increasing the number of antigens and considering the sera reaction to at least two different plasmodial antigens, this enabled limiting the false positive rates. However, this approach using solely antigenic peptides could lead to an underestimation of the level of transmission; thus, other serologic markers were included, such as the recombinant proteins MSP1 and AMA1, the use of which there is a consensus in the literature [27-29]. 
In 2009, Noor et al. observed a P. falciparum seroprevalence rate of $14.2 \%$ in adults above 50 years, $6.9 \%$ in children and an average of $9.9 \%$ when they tested the reactivity of 4769 sera to one or both serological markers PfMSP1 and PfAMA1 among Djiboutian population [14]. The same method was applied to the present work and produced a seroprevalence rate of $30.0 \%$. Moreover, when the reaction to at least one marker of the 11 peptides, PfMSP1 and PfAMA1 were combined, the seroprevalence increased to $56.6 \%$; finally, a seroprevalence rate of $33.5 \%$ was obtained when considering reactions to at least 2 of the 13 markers. In light of these observations, it can be deduced that the prevalence and, indirectly, the $P$. falciparum malaria transmission have declined by at least a factor of three in the past seven years. These results were consistent with the needs and obligations that lead to a pre-elimination goal in which the reduction of transmission is the most important key to pre-elimination [15].

\section{Multivariate logistic regression and Bayesian ordinal multinomial regression analysis}

All obtained models predicting the $P$. falciparum or $P$. vivax seropositivity status or the level of humeral immune response to $P$. falciparum or $P$. vivax antigens have shown that female gender, a high educational level and never having visited a malaria-endemic country more than one year were protective. Considering the mixed infection seropositivity status, the multivariate logistic regression model showed a protective effect of living at a distance $>1.5 \mathrm{Km}$ from rivers and lakes, in a rural area and not having had fever during the last month before the cross-sectional study. Only the model that predicted the $P$. falciparum seropositivity status showed a protective effect of younger ages between 15 and 40 years. As serological tools reflect the cumulative exposition [28], these observations suggest that the older populations were more exposed and that transmission was thus higher in the past. In the city of Djibouti, educational level is generally correlated with the level of wealth and therefore more accessibility to health facilities and prevention measures [30]. Historically, Ethiopia and Djibouti have maintained very important population exchanges in both directions. Therefore, it is normal to see certain Djiboutian populations settle there for long periods due to the far lower living costs when facing economic or social difficulties in the Republic of Djibouti [31]. Carteron in 1978 and Fox in 1991 have shown that Ethiopia was the most important provider of malaria cases to Djibouti $[7,32]$. This may explain the observation that living in malaria-endemic country (and especially Ethiopia) for more than one year was a risk factor for being seropositive to $P$ falciparum or $P$. vivax.

\section{Geographical distributions of $P$. falciparum and $P$. vivax}

In the city of Djibouti, the seroprevalence rates for both parasite species revealed hotspots on both sides of the main wadi, i.e., Ambouli wadi and the quarters of Arhiba and Balbala 4. Arhiba and Balbala 4 are quarters with significant migrant populations who regularly travel to and/or from Ethiopia [31]. There was an association between the decreasing of seroprevalent clusters to both species and the increase of the cluster distance to Ambouli wadi.

In the rest of the country, $P$. falciparum seroprevalence rates were higher in the southern regions (Dikhil and Ali-Sabieh), and in particular, hotspots were found along the land routes to Ethiopia, i.e., Tammiro/As-Eyla and Ali-Sabieh. These roads are regularly used by professional truckers, private users and migrants because they are the only two terrestrial roads to Ethiopia [33].

Plasmodium vivax seropositivity status was more balanced throughout the Djiboutian territory, with hotspots in the same locations in the southern regions as for $P$. falciparum. Because of the possibility of liver persistence of hypnozoïtes, $P$. vivax can spread more widely across the entire country in the case of incomplete treatment. $P$. vivax can be found where $P$. falciparum is no longer detectable and can sometimes be more prevalent, as could be the case in the neighbouring countries [34]. This situation might explain the high seroprevalence rates recorded in northern regions and suggests the occurrence of local transmission foci when Anopheles vectors exist.

\section{The path to pre-elimination}

Pre-elimination is a combination of technical feasibility, i.e., the baseline domestic malaria transmission combined with the importation-related transmission, and operational feasibility, which takes into consideration the country's government status, health status and information on populations at risk [13].

Compared to one recent work [14], the present serological study indirectly indicates that transmission may have decreased by three-fold in the past seven years for $P$. falciparum, even though some hotspots were the same as those found in the Dikhil region. This work, once combined with recent information provided by Noor et al. has shown that the Republic of Djibouti is likely on the correct path to pre-elimination with benefits that are threatened by the persistence of hotspots such as those in the Dikhil Region. Finding the same hotspots seven years later constitutes a serious threat to the success of the announced goal. Taking into account technical and operational feasibility, pre-elimination is possible only insofar as efficient control methods are implemented at all administrative and executive levels of authority. 


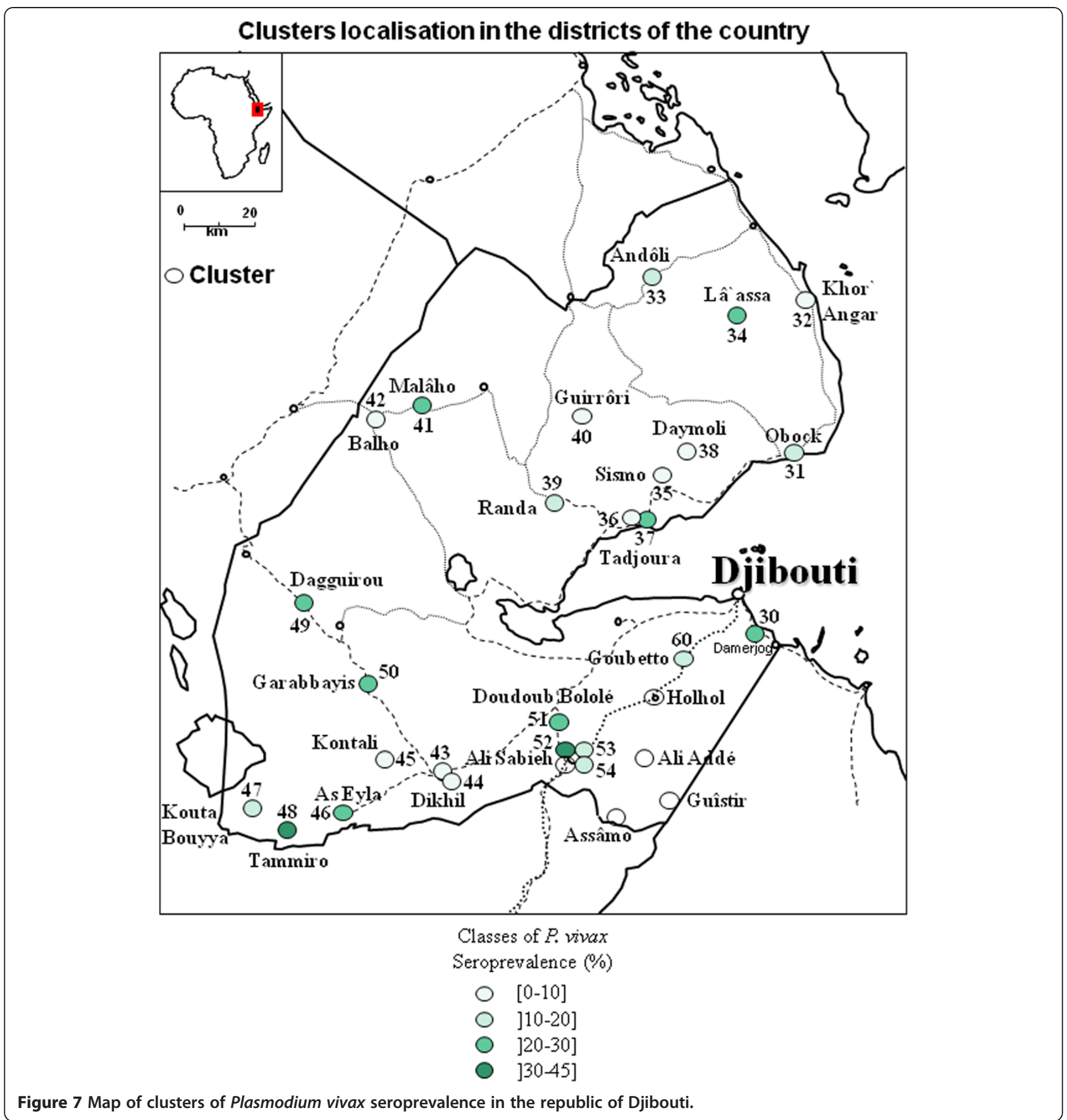

Recommendations emerge from the results of the statistical models. If the educational level of the population cannot be increased, pre-elimination will require increased awareness and health education for at-risk populations through methods that are appropriate to local realities. Although being female seems to be protective, health education should target mothers in particular to increase local knowledge, as has been previously done with HIV [35]. Regional collaborative alert systems are also indispensable because the population is regularly moving to a neighbouring country. To act efficiently on hotspots, the mass distribution of bed nets, mass chemotherapy and chemoprophylaxis for both parasites and indoor residual spraying should be performed, followed by serosurveys and vector monitoring. The vector monitoring system is actually debutant and in progress, although it primarily concerns Djibouti city. Border posts should also see an improvement of their monitoring activities and health controls. 


\section{Conclusions}

As seen in this study, the $P$. falciparum seroprevalence rate was $25.90 \%$ in 2002, further studies with the same population would be required to assess if there was a real decrease in transmission of $P$. falciparum in the Republic of Djibouti since 2002.

This is the first study that assessed the prevalence of $P$. vivax in the Republic of Djibouti. It is necessary to improve our knowledge of this pathogen in order to create an effective elimination programme.

The protective effect of female gender, educational level and never having visited a malaria-endemic area for more than one year was observed for both $P$. falciparum and $P$. vivax. For $P$. falciparum along, a protective effect was also observed for not having had a fever the last month, living $>1.5 \mathrm{~km}$ away from lakes and rivers and being younger in age.

These findings should encourage authorities to improve efforts toward elimination and to begin the final assault against the few persistent hotspots. However, to assess the real pre-elimination status, the precise level of both $P$. falciparum and $P$. vivax transmission should be regularly monitored by serological methods or other tools and including children less than five years old.

\section{Additional files}

Additional file 1: Bivariate logistic regression analysis of $P$. falciparum infection's seroprevalence for socio-economic variables.

Additional file 2: Bivariate logistic regression analysis of $P$. falciparum infection's seroprevalence for environmental, health and bed net use variables.

Additional file 3: Bivariate logistic regression analysis of $P$. vivax infection's seroprevalence for socio-economic variables.

Additional file 4: Bivariate logistic regression analysis of $P$. vivax infection's seroprevalence for environmental, health and bed net use variables.

Additional file 5: Bivariate logistic regression analysis of $P$. falciparum and $P$. vivax mixed infection's seroprevalence for socioeconomic variables.

Additional file 6: Bivariate logistic regression analysis of $P$. falciparum and $P$. vivax mixed infection's seroprevalence for environmental, health and bed net use variables

Additional file 7: Bivariate ordinal logistic regression analysis of the serological response to $P$. falciparum antigens

Additional file 8: Bivariate ordinal logistic regression analysis of the serological response to $P$. vivax antigens.

Additional file 9: $P$. falciparum, $P$. vivax seroprevalences and geographical localization of the Djiboutian clusters

Additional file 10: Map of clusters of $P$. falciparum and $P$. vivax seroprevalence in the capital of the Republic of Djibouti.

Additional file 11: Map of clusters of $P$. falciparum and $P$. vivax seroprevalence in the Republic of Djibouti.

\section{Authors' contributions}

$B A K, S B, H B, C R$ and BP conceived and designed the experiments. BAK, LO, MAK, IHF, HMA, AAA, MKW, SNA, HYD and CR collected the data. HB, AP, $B A K, S B, V M$ and $C T$ contributed to reagents/materials/analysis tools. SB, BAK, $H B, M A K, V M$ and $C R$ analysed the data. BAK, SB, AP, VM, CR and BP wrote the paper. All authors read and approved the final manuscript.

\section{Consent}

Blood samples were collected anonymously in accordance with the recommendations of the Djiboutian Ministry of Health, which also gave ethical approval for the study.

\section{Acknowledgements}

We thank Dr. Chris Drakeley from the London School of Hygiene and Tropical Medicine, London, UK, and Dr. Shirley Longacre from the Institut Pasteur à Paris, France, for providing the PfAMA1, PfMSP1, PVMSP1 ${ }_{42}$ and PVMSP1 19 recombinant proteins. This study was supported by the Délégation Générale pour l'Armement and the Direction Centrale du Service de Santé des Armées (grant no. 10co404 and grant no.10co405).

We also thank Dr. Michel ETCHEPARE and Dr. Christian TOSI who supervised the collection of blood samples with CR, and Dr. Mohamed Ali KAMIL of the Djiboutian Ministry of Health, who facilitated the field studies funded by the World Bank.

\section{Author details}

${ }^{1}$ Unité de Parasitologie, Département d'Infectiologie de Terrain, Institut de Recherche Biomédicale des Armées, Marseille, France. ${ }^{2}$ Aix Marseille Université, Unité de Recherche sur les Maladies Infectieuses et Tropicales Emergentes, UM 63, CNRS 7278, IRD 198, Inserm 1095, Marseille, France. ${ }^{3}$ Service de Santé des Forces Armées Djiboutiennes, Djibouti, République de Djibouti. ${ }^{4}$ Service des Maladies Infectieuses et Tropicales, Hôpital Général Peltier, Djibouti, République de Djibouti. ${ }^{5}$ Institut de Recherche Médicinale, Centre d'Etude et de Recherche de Djibouti, Djibouti, République de Djibouti. ${ }^{6}$ Observatoire Midi-Pyrénées, Laboratoire d'Aérologie, Centre National de le Recherche Scientifique, Université Paul Sabatier, Toulouse, France. ${ }^{7}$ Centre National d'Etudes Spatiales, Service Applications et Valorisation, Toulouse, France. ${ }^{8}$ Institut National de Santé Publique de Djibouti, Ministère de la Santé, Djibouti, République de Djibouti. ${ }^{9}$ Bureau Expertise des risques sanitaires, Sous-direction Action Scientifique et Technique, Direction Centrale du Service de Santé des Armées, Paris, France.

${ }^{10}$ Faculté des Sciences, Université de Djibouti, Djibouti, République de Djibouti. ${ }^{11}$ Institut Pasteur de Madagascar, Antananarivo, Madagascar.

Received: 3 September 2012 Accepted: 21 November 2012 Published: 28 November 2012

References

1. WHO: 2012. http://www.who.int/features/factfiles/malaria/fr/index.html accessed 6 May.

2. Roll back malaria. http://www.rbm.who.int/gmap/fr/2-4a.html accessed 6 May 2012.

3. Roll back malaria. http://www.rbm.who.int/gmap/fr/2-2a.html accessed 6 May 2012

4. Roll back Malaria. http://www.rbm.who.int/gmap/GMAP_Advocacyweb.pdf page-FR-9 accessed 6 May 2012.

5. Comesa. http://about.comesa.int/index.php?option=com content\&view= article\&id=95\&ltemid=117 accessed 6 May 2012.

6. Bouffard G: Quelques cas de fièvre paludéenne observés à Djibouti, Chef-lieu de la Côte des Somalis. Ann Hyg Med Col 1901, 4:440-452.

7. Carteron B, Morvan D, Rodhain F: The question of endemic malaria in Republic of Djibouti. Med Trop 1978, 38:299-304.

8. Rodier GR, Parra JP, Kamil M, Chakib SO, Cope SE: Recurrence and emergence of infectious diseases in Djibouti City. Bull World Health Organ 1995, 73:755-759.

9. Programme National de Lutte contre le Paludisme: Plan stratégique de lutte contre le paludisme 2006-2010. République de Djibouti: Ministère de la Santé; 2006

10. Rogier C, Pradines B, Bogreau H, Koeck JL, Kamil MA, Mercereau-Puijalon O: Malaria epidemic and drug resistance, Djibouti. Emerg Infect Dis 2005, 11:317-321. 
11. Bogreau H, Renaud F, Bouchiba H, Durand P, Assi SB, Henry MC, Garnotel E, Pradines B, Fusai T, Wade B, Adehossi E, Parola P, Kamil MA, Puijalon O, Rogier C: Genetic diversity and structure of African Plasmodium falciparum populations in urban and rural areas. AmJTrop Med Hyg 2006, 74:953-959.

12. Ollivier L, Nevin RL, Darar HY, Bougère J, Saleh M, Gidenne S, Maslin J, Anders D, Decam C, Todesco A, Khaireh BA, Ahmed AA: Malaria in the Republic of Djibouti, 1998-2009. AmJTrop Med Hyg 2011, 85:554-559.

13. Tatem AJ, Smith DL, Gething PW, Kabaria CW, Snow RW, Hay SI: Ranking of elimination feasibility between malaria-endemic countries. Lancet 2010, 376:1579-1591.

14. Noor AM, Mohamed MB, Mugyenyi CK, Osman MA, Guessod HH, Kabaria CW, Ahmed IA, Nyonda M, Cook J, Drakeley CJ, Mackinnon MJ, Snow RW: Establishing the extent of malaria transmission and challenges facing pre-elimination in the Republic of Djibouti. BMC Infect Dis 2011, 11:121.

15. GMAP a field technical review for low transmission area. http://www.rbm.who. int/gmap/fr/3-2.html accessed 6 May 2012.

16. Corran P, Coleman P, Riley E, Drakeley C: Serology: a robust indicator of malaria transmission intensity? Trends Parasitol 2007, 23:575-582.

17. Drakeley CJ, Cook J: Potential contribution of sero-epidemiological analysis for monitoring malaria control and elimination: historical and current perspectives. Adv Parasitol 2009, 69:299-352.

18. Youssef RM, Alegana VA, Amran J, Noor AM, Snow RW: Fever prevalence and management among three rural communities in the North West Zone, Somalia. East Mediterr Health J 2010, 16:595-601.

19. Bousema T, Youssef RM, Cook J, Cox J, Alegana VA, Amran J, Noor AM, Snow RW, Drakeley CJ: Serologic markers for detecting malaria in areas of low endemicity, Somalia, 2008. Emerg Infect Dis 2010, 16:392-399.

20. Maslin JR, Rogier C, Berger F, Khamil MA, Mattera D, Grandadam M, Caron $\mathrm{M}$, Nicand E: Epidemiology and genetic characterization of HIV-1 isolates in the general population of Djibouti (Horn of Africa). J Acquir Immune Defic Syndr 2005, 39:129-132.

21. Perera KL, Handunnetti SM, Holm I, Longacre S, Mendis K: Baculovirus merozoite surface protein $1 \mathrm{C}$-terminal recombinant antigens are highly protective in a natural primate model for human Plasmodium vivax malaria. Infect Immun 1998, 66:1500-1506.

22. Ambrosino E, Dumoulin C, Orlandi-Pradines E, Remoue F, Toure-Baldé A, Tall A, Biram Sarr J, Poinsignon A, Sokhna C, Puget K, Trape JF, Pascual A, Druilhe $P$, Fusai T, Rogier C: A multiplex assay for the simultaneous detection of antibodies against 15 Plasmodium falciparum and Anopheles gambiae saliva antigens. Malar J 2010, 9:e317.

23. DIVA-GIS. http://www.diva-gis.org.

24. Hu FB, Goldberg J, Hedeker D, Flay BR, Pentz MA: Comparison of population-averaged and subject-specific approaches for analyzing repeated binary outcomes. Am J Epidemiol 1998, 147:694-703.

25. Mickey RM, Greenland S: The impact of confounder selection criteria on effect estimation. Am J Epidemiol 1989, 129:125-137.

26. Abramo C, Fontes CJ, Krettli AU: Cross-reactivity between antibodies in the sera of individuals with leishmaniasis, toxoplasmosis, and Chagas disease and antigens of the blood-stage forms of Plasmodium falciparum determined by indirect immunofluorescence. AmJTrop Med Hyg 1995, 53:202-205

27. Corran PH, Cook J, Lynch C, Leendertse H, Alphaxard M, Griffin J, Cox J, Abeku T, Bousema T, Ghani AC, Drakeley CJ, Riley E: Dried blood spots as a source of anti-malarial antibodies for epidemiological studies. Malar J 2008, 7:e195.

28. Drakeley CJ, Corran PH, Coleman PG, Tongren JE, McDonald SL, Carneiro I, Malima R, Lusingu J, Manjurano A, Nkya WM, Lemnge MM, Cox J, Reyburn $H$, Riley EM: Estimating medium- and long-term trends in malaria transmission by using serological markers of malaria exposure. Proc Nat Acad Sci USA 2005, 102:5108-5113.

29. Okell LC, Ghani AC, Lyons E, Drakeley CJ: Submicroscopic infection in Plasmodium falciparum-endemic populations: a systematic review and meta-analysis. J Infect Dis 2009, 200:1509-1517.

30. Enquête Djiboutienne à Indicateurs Multiples. République de Djibouti: Ministère de la Santé; 2006:4-5.

31. Bilan 1999-2005 et Perspectives. République de Djibouti: Ministère de I'Intérieur; 45-46.

32. Fox E, Bouloumie J, Olson JG, Tible D, Lluberas M, Shakib SO, Parra JP, Rodier G: Plasmodium falciparum travels by train from Ethiopia to Djibouti. Med Trop 1991, 51:185-189.
33. Rapport d'activité. République de Djibouti: Ministère du Transport; 2008:5-6.

34. Alemu A, Tsegaye W, Golassa L, Abebe G: Urban malaria and associated risk factors in Jimma town, south-west Ethiopia. Malar J 2011, 10:173. 24.

35. Programme National de Lutte contre le Sida: Plan stratégique de lutte contre le VIH/SIDA 2006-2010. République de Djibouti: Ministère de la Santé.

doi:10.1186/1475-2875-11-395

Cite this article as: Khaireh et al:: Plasmodium vivax and Plasmodium falciparum infections in the Republic of Djibouti: evaluation of their prevalence and potential determinants. Malaria Journal 2012 11:395.

\section{Submit your next manuscript to BioMed Central and take full advantage of:}

- Convenient online submission

- Thorough peer review

- No space constraints or color figure charges

- Immediate publication on acceptance

- Inclusion in PubMed, CAS, Scopus and Google Scholar

- Research which is freely available for redistribution

Submit your manuscript at www.biomedcentral.com/submit
C Biomed Central 